\title{
Automatic Spot Welding of Ventilation Spacers on Lamination Sheet Using Robotic Work Cell
}

\author{
Deepak Sachan, Avinash Patil, and Subrata Biswas
}

\begin{abstract}
Stringent production targets, competition in global market and reduced man power have highlighted the need for automation in all major work areas of manufacturing organizations to gain higher productivity. As the demand for power is increasing, power equipment manufacturing companies need to make more efforts for automating core technology areas for productivity improvements. Spot welding of ventilation spacers for generators is one such area which can benefit heavily from automation from automatic robotic welding process. Ventilation laminations are required for cooling the stator core of the steam turbine generator and are manufactured by welding ventilation spacers on a lamination sheets using resistance welding (spot welding) process.
\end{abstract}

The present paper proposes an automated apparatus and a method for spot welding of ventilation spacers on lamination sheets of various ratings of turbo generators, using a robot that holds and moves the work piece at a fixed spot welding machine to improve the productivity and quality of welds.

Index Terms-Automated spot welding, robotic spot welding, fixed spot welding machine, ventilation spacers, turbo generator.

\section{INTRODUCTION}

Robotic welding research deals with the relevant technical and scientific aspects involved in the task of reproducing the work of the experienced and skilled human welder. Welding was, for a long time, a task performed only by humans, being a craft that combines skill with art and science. Automating welding is therefore a very difficult and demanding objective; because of the required adaptive behavior of the automatic system [1].

Ventilation laminations are required for cooling the stator core of the steam turbine generator and are manufactured by welding ventilation spacers on a lamination sheets using resistance welding (spot welding) process. The lamination sheet is made up of silicon steel, having thickness $0.65 \mathrm{~mm}$. The ventilation spacers are made up of mild steel of various thicknesses. At present three types of spacers are being used depending on the generator rating.

1) Square cross section bar (side length: $5 \mathrm{~mm}$ )

2) Section (5 mm width and $10 \mathrm{~mm}$ thickness)

3) Section (8 mm width and 10mm thickness)

These Ventilations spacers are required to be welded to the lamination sheets using spot welding process. For a typical $270 \mathrm{MW}$ rated generator, 35 to 40 spacers are required to be welded to one lamination sheet (Fig. 1). Each spacer bar

Manuscript received May 17, 2015; revised October 26, 2015.

The authors are with BHEL, India (email: deepaksachan@bhelrnd.co.in, avinashp@bhelrnd.co.in, sbiswas@bhel.in). requires welds at minimum 3 locations totaling to around 120 welding locations on a single lamination sheet. With the existing manual process, the time required for welding a complete lamination is very large (45 minutes approx.). The manual welding process not only causes fatigue on operator but is also time consuming causing reduction in productivity. Using an automated process with a robotic work cell, it is estimated that the time can be reduced by $75 \%$ (15 minutes), thus improving productivity and reduction in fatigue on operator.

The time saving will be primarily by cutting down the intermediate non-productive time of accurate repositioning and because of the accurate positioning the weld quality will also be improved. Hence the Cycle time will reduce and the quality of the weld will be improved. As spot welding process is a dangerous process hence because of the introduction of robot the fatigue and hazardous conditions on operators will also be reduced drastically.

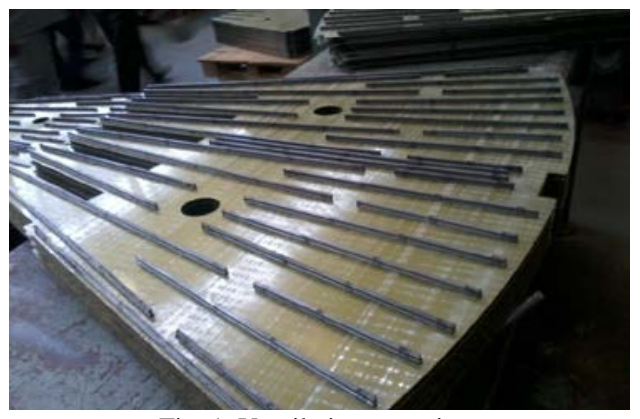

Fig. 1. Ventilation stamping.

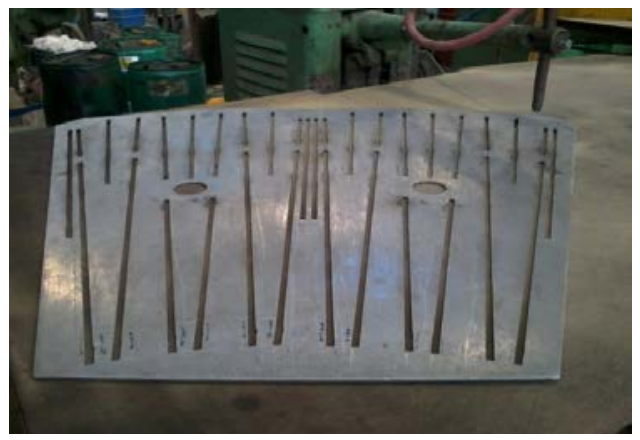

Fig. 2. Template with slots for ventilation spacers.

\section{EXISTING PROCESS}

Two types of spot welding processes, manual and automatic, are widely used in the industry for the spot welding of ventilation spacers.

\section{A. Manual Process}

The lamination sheet as well template has two large holes 
at the same location that act as reference for assembly.

In the manual process, the mandrels are first inserted from bottom of lamination sheet through the reference holes. Then the template having slots for the ventilation spacers is placed on the lamination sheet (Fig. 2). With reference to the template slots, the spacers of suitable length are inserted in the slots. The entire assembly consisting of lamination, template and ventilation spacers can be moved simultaneously in $\mathrm{X}-\mathrm{Y}$ directions with the help of mandrels.

The spot welding process is carried out by positioning the required point at the stationary spot welding gun (Fig. 4) and operating the spot welding gun through a foot switch (Fig. 3(a), 3(b)).

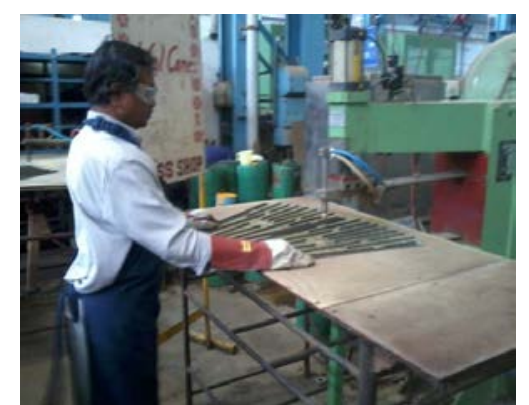

Fig. 3(a). Operator performing the spot welding.

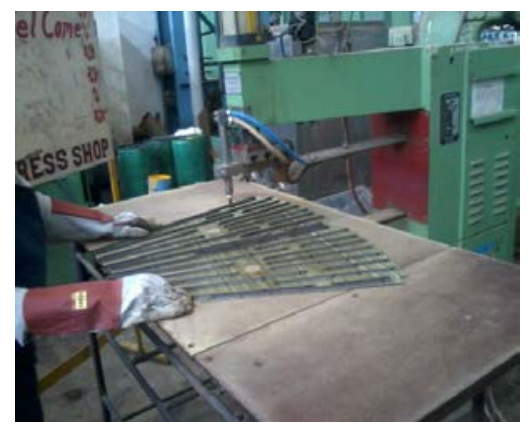

Fig. 4(b). Operator performing the spot welding.

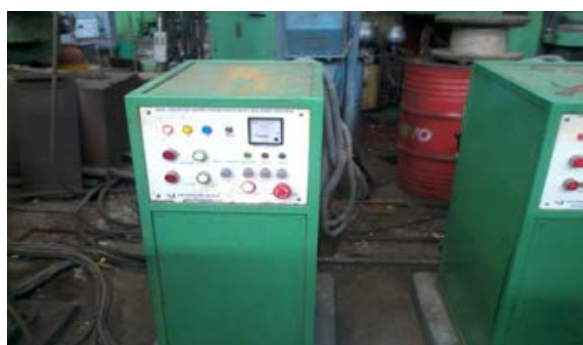

Fig. 4. Fixed spot welding machine [2].

The actual manual spot welding process is carried out in two steps. In first step, the entire assembly moved by holding the two mandrels and welding at least one weld point on each ventilation spacer. In second step, remaining points are welded. As, a typical $270 \mathrm{MW}$ capacity generator consists of 40 spacers of different lengths and about 120 welds, it takes a long time for welding the ventilation spacers on one lamination sheet.

\section{B. Automated Process}

Robotic spot welding is the solution for high volume production for high volume manufacturers who need to perform thousands of spot welds per shift and where welding cycle time is critical [3]. Two types of spot welding guns, pneumatically controlled and servo controlled are typically used with the robotic spot welding systems. In servo controlled weld gun, using a spare robot axis to actuate the weld gun gives added benefits than a pneumatic weld gun The servo spot welding process uses an additional servo motor and encoder (7th axis) of the robot to drive and control the clamping force of the welding electrodes. Some automated apparatus and methods have been previously employed for spot welding of ventilation spacers on lamination sheets where the robot is carrying a servo spot welding gun attached to it as shown in the Fig. 5.

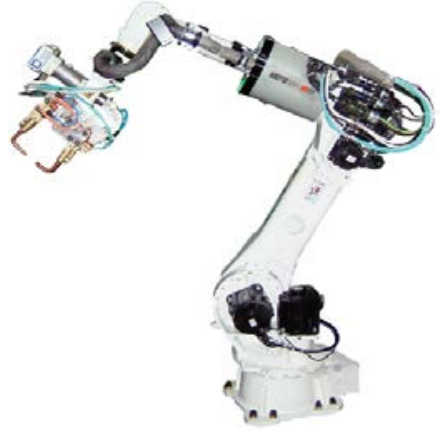

Fig. 5. Spot welding machine gun attached with robot.

In this type of automated process, the ventilation lamination with ventilations spacers and template is fixed on a structure and the robot with the spot welding gun will move to each weld point and perform the welding. Generally these types of spot welding robots are used where the robot has to move over a complex geometric path in $\mathrm{X}, \mathrm{Y}$ and $\mathrm{Z}$ directions e.g. parts in automobile industry. For such an application large robots, having payloads of 150 to $200 \mathrm{Kg}$., are required as the spot welding gun transformers are heavy. Because of the robotic spot welding gun and large capacity robot this process is very costly [4].

\section{PROPOSED SYSTEM SET-UP AND WORKING}

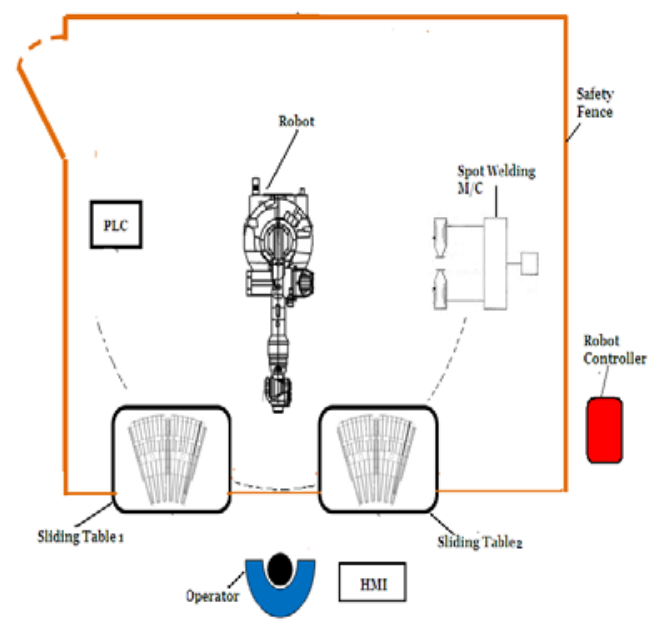

Fig. 6. Process layout.

The process will begin by making a completely assembly of lamination sheet, template and ventilation spacers and will be put over a supporting structure (Fig. 7). The supporting structure is required to provide support from bottom to the complete assembly to prevent the sag. 
In this system, the spot welding machine will be fixed and robot will hold the assembly consisting of lamination sheet along with the template and ventilations spacers by an end of arm tool attached to the wrist of the robot.

The system will consist of two sliding tables that can move in out of the robotic cell. Each sliding table is a dual purpose (load and unload) and can be used for loading the assembly consisting of lamination sheet with template and ventilation bars and unloading the finished product (Fig. 6).

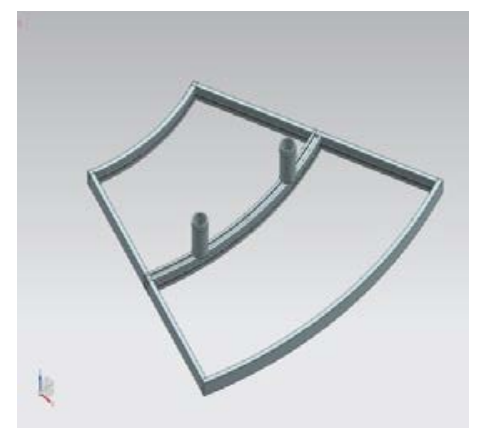

Fig. 7. supporting structure.

The robot end of arm tool (EOAT) will comprise of two pneumatically operated three- jaw grippers attached to a solid frame (Fig. 8). This EOAT will be attached to the robot wrist. Using the pneumatic grippers, the robot will lift the complete assembly gripping the two cups attached to the supporting structure. The only limitation with the system is that the total weight of whole assembly comprising of support structure, lamination sheet, template, bars and EOAT should not be more than the pay load capacity of robot.

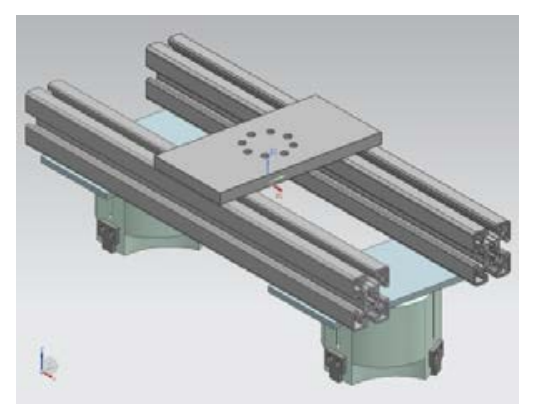

Fig. 8. EOAT.

The robot with correct payload, with a factor of safety, will be selected to support the total weight of the EOAT and the assembly comprising of lamination sheet, template, ventilation spacers, supporting structure and other accessories.

The control system will consist of a Programmable Logic Controller (PLC) that will communicate with the robot using Ethernet IP protocol. All the peripheral equipment such as sliding tables will be controlled by PLC whereas the EOAT will be controlled by robot.

The robot program will directly be generated through the CAD drawing of the ventilation sheet [5].

\section{THE PROCESS FLOW}

Operator will manually load the lamination sheet, on the Sliding Table I After inserting lamination sheet in the holding cups mounted on the supporting structure, operator will then insert the slotted template in the holding cups. With reference to the slots of the template, the operator will then insert required ventilation spacers of suitable length in the slots.

Operator will press the 'Ready' button on operator pendant. The lamination sheet assembly comprising of lamination sheet, template and ventilation spacers will move inside the robotic work cell and will be ready for pickup by the robot. The robot, after receiving the signal from PLC, will move from its home position to the 'Sliding Table I' and pick the entire assembly holding the cups using two three- jaw grippers. Robot will then move to the spot welding machine. Robot will be programmed in such a way so that the entire assembly is moved in $\mathrm{X}-\mathrm{Y}$ direction and positioned at different locations with reference to the weld points. In this case the spot welding machine is stationary and robot is moving the assembly as per the weld point locations. While the robot is moving the lamination assembly for the welding, the operator will carry out the task of making other lamination assembly on Sliding Table II by placing a lamination sheet, template and required ventilation spacers. After completion of assembly task, the operator will push the 'Ready' button on operator pendant and the entire assembly will move in the robotic cell for the robot to pick up the assembly. The welding will be done by spot welding machine while robot will be moving the complete assembly as per a pre programmed pathe generated from the CAD model oft he ventilation sheet. After welding is finished the robot will move to the Sliding Table I to place the welded assembly. After placing the completed welding assembly on 'Sliding Table I' and after getting the 'Ready' signal from sliding Table II, the robot will then go to Sliding Table II and pickup the second lamination assembly. Operator will unload the finished component and load a new one on Sliding Table I and the process repeats. In the proposed process, the welding will be finished within a quick span of time without much human intervention. This process will increase the productivity and reduce the fatigue on the operator.

\section{Benefits of the Proposed Process}

The proposed process will have following benefits:

- Elimination of the manual handling of the lamination sheet during the welding process.

- Improvement in the productivity by reducing the total cycle time

- Enhancement of the quality of weld joints.

- Better work environment.

- Minimisation of the product rejection rates

- Reduction in operator fatigue

\section{CONCLUSION}

Robotic automation in welding process includes benefits that range from improved weld quality to decreased human intervention and fatigue.

The system for manufacturing the spot welded ventilation laminations with a smaller robot and fixed spot welding 
machine is economical than that of a large robot holding the spot welding gun.

\section{REFERENCES}

[1] J. Norberto Pires, Altino Loureiro, and Gunnar Bölmsjo, Welding Robots Technology: System Issues and Applications, Springer, 2005.

[2] Spot welding machine. [Online]. Avaiable: http://www.growcontrols.com

[3] S. R. Deb, Robotics Technology and Flexible Automation, Mc Graw Hill, 2004.

[4] J. Magar and R. Shelkikar, "Implementation of robots in spot welding process," IOSR Journal of Electronics and Communication Engineering, vol. 5, no. 3, April 2013.
[5] P. Neto, J. Norberto Pires, and A. Paulo Moreira, "CAD based off-line robot programming,” TELKOMNIKA, vol.11, no.11, pp. 6267-6273, November 2013,.

Deepak Sachan was born at Kanpur, India on March 1, 1986. He is graduated in electronics and communication engineering from Madan Mohan Malviya Technical University Gorakhpur India in 2009.

He has been working as a senior engineer at the Technology Development Lab at Bharat Heavy Electricals Limited corporate Research and Development Center since 2010. 